\title{
Public Perceptions of the Role of Traditional Medicine in the Health Care Delivery System in Ghana
}

\author{
Razak Mohammed Gyasi (Corresponding Author) \\ Department of Geography and Rural Development, KNUST, Kumasi, Ghana \\ Postal Box 3419, Kumasi, Ghana \\ Tel: 233-243-235-414Ｅ-mail: binghi_econ@yahoo.com
}

Charlotte Monica Mensah

Department of Geography and Rural Development, KNUST, Kumasi, Ghana

Tel: 233-207-732-713_E-mail: charlottemensah2002@yahoo.ca

Prince Osei-Wusu Adjei

Department of Geography and Rural Development, KNUST, Kumasi, Ghana

Tel: 233-243-126-093Ｅ-mail: princeosei2@hotmail.com.

Seth Agyemang

Department of Geography and Rural Development, KNUST, Kumasi, Ghana

Tel: 233-243-237-658_E-mail: sagye123@yahoo.co.uk

Received: January 27, 2011 Accepted: February 10, 2011 doi:10.5539/gjhs.v3n2p40

\begin{abstract}
Background: People from different cultural backgrounds have used different forms of Traditional Medicine as a means to managing their ailments. This study examined public perceptions of the role of Traditional Medicine in relation to the accessibility, conditions treated, safety, efficacy rate and interactions between traditional and orthodox medical systems in the Sekyere South District of Ashanti, Ghana. Methods: This was a descriptive cross-sectional survey. A sample of 70 Traditional Medical Practitioners, 30 health care users, and 20 Orthodox Medical Practitioners were used and selected respectively based on snowball, random sampling and purposive techniques. Both quantitative and qualitative data were collected through administered-questionnaire and in-depth interviews. Non-participant observation was used to assess the working environments of the practitioners in 9 selected communities in the district. Relevant data obtained were analysed using both qualitative and quantitative methods. Percentages and cross-tabulations, using the Predictive Analytic Software (PASW), version i6.0 were the methods used to analyse the data.

Findings: The main findings suggest that Traditional Medicine is effective as it was employed in treating numerous medical conditions such as malaria, typhoid fever, arthritis, jaundice, impotency, infertility, stroke, broken bones, boils, piles, HIV/AIDS, mental illness, etc. However, safety of use of the Traditional Medicine is not standardized. Moreover, there is some form of interaction between the two health care providers through cross-referrals though; the cross-referral systems are not coordinated and strictly unofficial. Traditional Medicine is readily available to the people and also less expensive, hence easily accessible. Policy options that seek to address some difficulties and challenges encountered by the practices of Traditional Medicine and improving upon the quality, safety, and standard of service are recommended. Conclusion: The conclusion drawn from the research is that Traditional Medicine is used by many people to managing numerous conditions. It is accessible and effective. It therefore plays a significant role by reducing life-threatening ailments of humanity. This study adds to the scant but growing documented literature about the potentials of Traditional Medicine.
\end{abstract}


Keywords: Traditional Medicine, Accessibility, Arthritis, Orthodox medicine, Ghana

\section{Introduction}

Ailments have over the years been a scourge and a threat to mankind. People from different cultural backgrounds have used different herbal plants, plant extracts, animal products and mineral substances (Addae-Mensah, 1992) as the means to care, cure and treat ill-health, with disease prevention, and with health promotion (Curtis and Taket, 1996) since pre-historic times.

Traditional Medicine (TM) embraces the ways of protecting and restoring health that existed before the arrival of orthodox medicine (OM) (World Health Organisation [WHO], 2001). WHO therefore defines TM as diverse health practices, approaches, knowledge and beliefs incorporating plant, animal, and/or mineral based medicines, spiritual therapies, manual techniques and exercises applied singularly or in combination to maintain well-being, as well as to treat, diagnose or prevent illness (WHO, 2002; 2000). Buor (1993) in his study on impacts of TM in the health care delivery services in Ghana argues that TM involves the use by the folk population primarily of unorthodox and unscientific method for curative and prevention of diseases. It has been debated whether the word "traditional" should be used at all, as it implies some degree of stagnancy or backwardness (Hougen et al, 1998).

TM is assuming greater importance in the primary health care of individuals and communities in many developing countries (Peltzer and Mngqundaniso, 2008; WHO, 2002; 1978). These approaches to health care belong to the traditions of each culture, and have been handed down from generation to generation (WHO, 1996). China and India, for example, have developed very sophisticated contemporary and alternative medicine systems such as acupuncture and ayurvedic for decades (Addae-Mensah, 2002; Agyare et al, 2006). In fact, TM reflects the socio-religious structure of indigenous societies from which it developed, together with the values, behaviours and practices within their communities. TM ultimately aims at restoring the physical, mental and social wellbeing of the patient, through alternative health care delivery to the orthodox medical system.

Tribes, cultures and indigenous people of nations throughout the world have evolved system of TM for generations, and communities have found most of these medical practices valuable and affordable and still depend on them for their health care needs. The WHO estimates that about $60 \%$ of the world's people uses herbal medicine for treating their sicknesses and up to $80 \%$ of the population living in the African Region depends on TM for some aspects of primary health care (WHO, 2000). Indeed, in rural communities in Ghana, like other developing countries and elsewhere, TM will continue to remain a vital and permanent part of the people's own health care system.

The efficacy and potency of TM are indeed attracting global attention (Peltzer and Mngqundaniso, 2008; Mwangi, 2004; Buor, 1993) and that traditional, complementary and alternative medicine is globally increasing in popularity (Kaboru et al, 2006). The global trend indicates that even in the advanced countries, more people with the most advanced and sophisticated OM system are making headway in TM use to cater for their health care requirements (WHO, 2001). Studies have shown that, almost 70\% of the population in Australia used at least one form of contemporary and alternative medicine (CAM), and 44.1\% visited CAM practitioners in 2007. Also, the annual 'out of pocket' expenditure on CAM, nationally, was estimated at US\$ 3.12 billion (Xue et al, 2010). In the Netherlands, $60 \%$, while in the United Kingdom, $74 \%$ of the people are advocating for the inclusion of CAM into the National Health Service. The percentage of the population which has used CAM at least once in Canada, France, USA and Belgium stands at $70 \%, 75 \%, 42 \%$ and $38 \%$ respectively (WHO, 2002). A survey conducted in the member states of the European Union in 1991 revealed that 1,400 herbal drugs were used in the European Economic Community by patients (WHO, 1996). One-third of American adults have also used alternative treatment and there is a fast growing interest in CAM system in the developed world (WHO, 2001; 1996).

WHO reported in 2001 that in Malaysia, about US\$ 500 million is spent annually on TM compared to only about US\$ 300 million on OM. In China, TM accounts for 30-50\% of the total population consumption (WHO, 1998). Sri Lanka steadily worked towards the goal of enhancing the effectiveness of TM, such that, now, even the highly literate consult TMPs before visiting orthodox health institutions (Aluwihare, 1982; Buor, 1993; Peltzer, 1998, 2000a, 2003; Wilkinson and Wilkinson, 1998; Ndulo, 2001). Majority of Sri Lankans, estimated at 55-60\% rely on TM and traditional birth attendants (WHO, 2001). Indeed, in 1996, the total annual sales of herbal medicines reached US\$ 14 billion worldwide (WHO, 2001). In countries for which more detailed data are available, the percentage of the population that uses TM ranges from $90 \%$ in Burundi and Ethiopia, to $80 \%$ in Burkina Faso, the Democratic Republic of Congo and South Africa; 70\% in Benin, Cote d'Ivoire, Ghana, Mali, Rwanda and Sudan; and $60 \%$ in Tanzania and Uganda (WHO, 2000). A study published by UNAIDS shows that about two-thirds of HIV/AIDS patients in developing countries use TM to obtain symptomatic relief, manage opportunistic infections and boost their immune systems (UNAIDS, 2003; Osei-Edwards, 2003). The medicines used by the practitioners 
to treat AIDS patients are rightly available locally (WHO, 2001). Their familiarity with patients and also the communities in which they operate serve as an added advantage to relief the AIDS patients. The traditional healers are recognised, acknowledged and trusted in their communities; they could therefore be used as counsellors and health educators to cure the spread of STIs, HIV and AIDS in Africa (ibid).

Furtherance, $60 \%$ of the children with high fever due to malaria was successfully treated with herbal medicines in Ghana, Mali, Nigeria and Zambia in 1998 (WHO, 2001). Indeed, the use of TM and the services of traditional healers by millions of Africans have been recognised by the WHO and in 1977, the World Health Assembly (WHA) drew attention to the potentials and the efficacy of herbal medicine in the national health care systems. The WHA urged member countries to utilise those medicines (Akerele, 1987; Nakajima, 1987) to broaden the coverage of health care in their respective countries. The malaria endemic countries in Africa have herbs for treating the fever. According to Buor (1993) and Awadh, et al (2004) the malaria parasite, especially the plasmodium falciparum has developed resistance to almost all the anti-malaria drugs and there is the need to develop herbal substitutes not only for the chemical side effects of orthodox medicine but also for the expensiveness of the orthodox health care.

In Ghana, up to the middle of the $19^{\text {th }}$ century, most indigenous people had no access to OM and relied entirely on herbal and other traditional medical services for their primary health care needs (Tchiakpe, 2004: unpublished master's thesis). With the scarcity of orthodox doctors, nurses and paucity of modern hospitals and clinics, the large majorities of people have to rely on sources other than OM and treatment. For example, in Ghana there is one traditional practitioner to approximately 386 people, whilst the ratio of orthodox doctors to population stands at 1:10 700; nurses to population ratio is 1:1 $578(\mathrm{MOH}, 2006)$.

People's own perception of the role of TM is not explicitly studied in Ghana. There are numerous expressions associated with the potentials of TM. Exploring these concerns will inform decision towards its improvement and sustainability. In this current paper we primarily analyse the public perceptions of the role of TM in the health care delivery system in Sekyere South District of Ashanti Region, Ghana.

\section{Methodology}

\subsection{Study setting and sampling}

The study was conducted between September, 2009 and May, 2010 in the Sekyere South District of Ashanti Region, Ghana. The Sekyere South District is one of the 27 political and administrative districts in the Ashanti Region with Agona as capital. The district spans a total area of $520 \mathrm{~km}^{2}$ and forms approximately $3.27 \%$ of the total landmass of the region. It is located in the north-eastern portion of Ashanti Region and shares boundaries with Ejura-Sekyedumase to the North, Mampong Municipal to the East, Sekyere East and Kwabre to the south and Offinso Municipal to the West. Specifically, the district lies between latitudes $6^{0} 50^{\prime} \mathrm{N}$ and $7^{0} 10^{\prime} \mathrm{N}$ and longitudes $1^{0} 40^{\prime} \mathrm{N}$ and $1^{0} 25^{\prime} \mathrm{N}$. The predominant economic activity in the district is subsistence farming. There are over 38 communities with only 9 health facilities which are made up of 2 hospitals, 1 maternity home and 6 health centres. Out of the 9 health facilities, the government owns 5 and the remaining 4 health facilities were established by missions.

The district has an estimated population of 82351 people with 51\% rural (Sekyere South District Assembly, 2009). The target population from which the sample was drawn was 5 619. A sample size of 120 was used. In all, 70 respondents representing the local people who had used the services of traditional health care providers, 30 Traditional Medical Practitioners (TMPs) and 20 Orthodox Medical Practitioners (OMPs) or health agency staff (doctors, medical assistants, nurses, midwifes, pharmacists, etc) constituted the sample size of the study. The various sub-samples were categorised based on their composition in the target population of the study. The research communities were: Wiamoase, Agona, Jamasi, Asamang, Daban, Cannan, Asiribusu, Funifuni and Kona. The overriding factors in their selection were the fair and adequate coverage of the district to ensure representativeness of findings. The allocation of the respondents to the communities took to consideration the sizes of their population.

\subsection{Data collection tools and procedure}

Both secondary and primary sources of data were considered in the course of the study. Records stored in various forms at the health units, departments and agencies in the district (e.g. District Assembly, District Health Administration, etc) were retrieved to assist in the record review in the course of the study. In addition, primary data on practices of TMPs, interactions between the two medical systems, efficacy, safety, client, etc of TM were collected by means of unstructured interview using open-ended and close response types of questions. The effectiveness and safety of TM were entirely measured with the respondent's responses and observation for reasons of logistics. 
A descriptive cross-sectional study and a combination of sampling methods were employed to obtain information from the respondents. Snowball technique was used to select the TMPs, simple random sampling was used to select the clientele of TM and the OMPs were purposively selected from the target population. On reaching the field, the sub-samples for each community were sub-divided to reflect the categories of the target population for the purpose of interview. Twi (a local dialect of the study area) and English were used to administer the interviews. The respondents and opinion leaders in each selected community were notified and briefed on the objectives of the research and asked for permission before interview begun. The interviewees were assured of strict confidentiality of the information they disclose. Each interview lasted for about 45 minutes. Detailed notes were taken and those in Twi were then translated into English. Non-participant observation was also used to assess the working environments or the sanitary conditions of the various traditional clinics, as hygiene was used to measure safety of use of TM in this study.

\subsection{Data analysis}

Both quantitative and qualitative approaches were considered. The quantitative data were ordered, coded, edited and entered into the computer and analysed using SPSS version 16.0 statistical software. The results of the study were displayed by frequency distribution tabulations. The notes and transcripts obtained from the interviews, after translated to English were presented. The major issues and the concerns of the respondents were edited and presented through direct quotation techniques.

Ethical approval was obtained from the Department of Geography and Rural Development, Kwame Nkrumah University of Science and Technology, Kumasi, Ghana. Permission was also granted from Sekyere South District administrative and health authorities, including traditional leaders in the district. Informed consent was obtained from all participants prior to the research.

\section{Results}

The results of the study are organized into four dimensions: accessibility and usage of TM, common conditions or diseases treated, perceptions on efficacy and safety of TM as well as the relationship existing between TM and biomedical system. Within each category, sub-themes as to how the set objectives of the study were accomplished are outlined.

\subsection{Accessibility and utilisation of Traditional Medicine}

In this study, accessibility is defined in connection with economic and physical parameters. That is how both distance and financial constraints influence health care use.

\subsubsection{Economic accessibility}

Poverty is a strong barrier to the utilization of health care services. The study reports that certain aspects of the $\mathrm{TM}$ are found to be cheaper and more readily available to the people than the orthodox medicine. Most people in the Sekyere South District are poor, who live below US\$1.25 a day, hence, find the orthodox medical care relatively costly to access.

$<$ Table 1>

Table 1 indicates that 58.6\% users of traditional health care services claimed that traditional medical services are "cheap" in comparable with the orthodox medical services. However, only $7.1 \%$ considered the service to be "expensive" relative to the orthodox medical services. TM is therefore the first point of call to many people in the study area. This presupposes that most of the rural poor entirely rely on the TM for almost all their health care needs.

\subsubsection{Physical accessibility}

The study has demonstrated that most of the settlements in the District are isolated, (especially the villages and hamlets) and the distances from these settlements to the health centres are long enough. This distant decay reduces the spatial interactions that should exist between these villages and the towns where health centres are located. Patients from Asiribusu, Kyirenfa, Abankoro, Saasua and Kokoteasua have to cover over 25 kilometres on foot in order to utilise the two health centres in Wiamoase. It was further observed that the roads linking these villages and the few health centres were in very bad state which becomes completely not motorable in the rainy seasons. Few drivers who risk and ply the roads charge exorbitant fares for short distances they cover. The following quotations attest to this.

'I'm very sick. I'm suffering from typhoid fever but we don't have a health centre here in this village. I don't also have GHC 3 to pay in and out lorry fare to go to Wiamoase (a $7.4 \mathrm{~km}$ distance) to see the doctor. I always go to herbalists who are with us here for herbal medicine", 
"Because of the high lorry fare, I sometimes prefer to walk to Bepoase (a distance of over 4.2 kilometres) to access the health post, although the distance is very long. Most people, especially the aged forgo clinic attendance altogether and resort to the immediate Traditional Medicines to manage their chronic and infectious diseases",

"Even if you have the money it is very risky to send a sick person all the way to Agona to see the doctor. His condition might even be worsen in the process and die as a result. It is very sad"'.

\subsection{Common medical conditions or diseases treated}

TMPs interviewed in the course of the research were into four categories: Traditional Birth Attendants (TBAs), Traditional Doctors (Herbalists), Faith healers and Diviners. They treated various diseases and promoted health using plant and plant products (e.g. leaves, bark, roots, trunk and flowers), prayers, holy water, Qur'an, Bible, magic powers, animals and mineral substances. It was found that the healers treated various medical conditions.

\section{$<$ Table 2>}

Most Traditional healers seem to be more specialised in conditions such as Malaria, Typhoid fever, rheumatism/arthritis, broken bones/fracture, and piles in the Sekyere South District. Few TMPs were found to engage in the treatment of such diseases as mental illness, HIV/AIDS, and heart attack. Looking at the different illnesses treated, traditional healers seem to play an important role in primary health care.

\subsection{Perceptions on efficacy and safety of Traditional Medicine}

\subsubsection{Perceptions on Safety of Clients at the Herbal Clinics}

The hygienic and the sanitary conditions of the practice environs of the TMPs were used to measure safety of patients at the herbal clinics. It was found that 37 (52.9\%) of clients of TM and $15(75 \%)$ of the OMPs claimed that the use of TM is not safe as compared with the use of OM. However, only $12(17.1 \%)$ and $1(5.0 \%)$ of users and OMPs respectively describe traditional medicinal usage as remarkably safe and totally out of harm's way.

"The TMPs operating in this community do not keep in and around their clinics clean. Also, a chunk of them hardly wash their plant products and other substances before concoction, decoction and other preparations are made. My father sustained serious infections soon after he had treated his typhoid fever with some herbal preparations and nearly died out of it. To me, Traditional Medicines have curative power to deal with many diseases, but most of them are not safe"'.

It was reported that the TMPs did not have standard and accurate dosage of medications. They prescribed medicines based on "trial and error" method. In an interview, a nurse stated that:

'Most of the TMPs are illiterate and hardly, know the chemical composition of the herbs and other substances they use. This could be dangerous and can be a threat to the health of their clients",

\subsubsection{Perceptions on Efficacy of Traditional Medicine}

Table 3 illustrates the different views given by TM clients in relation to efficacy. 42 (60\%) of clients and 11 (55\%) of the OMPs responded "very good" to the efficacy of TM while 23 clients; 6 OMPs and 5 clients; 3 OMPs respectively said TM is 'good" and 'bad"' in terms of efficacy. Some said they have used some aspect of TM and the effect was positive by achieving the aims for which the medicine were used. However, very few cases were reported concerning the medicine's inability to cure their medical problems.

\section{$<$ Table 3>}

The quotes that illustrate these points are below.

" My husband was hit with cerebrovascular disease, that is, stroke for over ten years and couldn't find treatment after several visits to the modern hospitals. It took only the intervention of a traditional healer in Jamasi. Now, he is physically fit and healthy and has started working. I believe that most of the TM are very effective""

" $T M$, the herbs in particular, are all that I rely on for all my ailments because they are potent to cure diseases right from the blood once and for all".

\subsection{Interactions between TMPs and OMPs}

The study illustrated that there was no officially sanctioned referral system between traditional and orthodox medical systems in the district. Almost all the referrals of patients occurred unofficially in an uncoordinated manner. The study has revealed that OMPs refer fewer patients to the TMPs, than the reverse. Out of the 30 TMPs involved in the study, $12(40 \%)$ said they had referred patients to conventional hospitals. This was sharp a contrast when it was found that 3 (15\%) out of 20 OMPs had referred cases to traditional clinics. This involved diseases of spiritual nature, broken bones, piles, rheumatism, boils, impotency, infertility, etc. In general, the degree of 
interaction between the OMPs and TMPs through referral cases is very low. This suggests that both practitioners compete for the clients. This development negatively affects the government's policy to integrate TM into the health care delivery system of the country $(\mathrm{MOH}, 2002)$ and must be addressed before the attempt to achieve the integration of medical systems in Ghana.

\subsection{The integration of Traditional Medical Service into the National Health Service}

It was found that the TMPs are prepared to join the mainstream health care system.

\section{$<$ Table 4>}

Twenty nine (95.0\%) of the 30 TMPs answered 'yes' when they were ask whether to fully integrate their services into the biomedical system or not. This is really affirmative action. Also, 96.7\% of TMPs were ready to go through all the necessary training that would enhance their skills in health care delivery. It is important then for the OMPs to recognise the TMPs as equally competent counterparts in the health system so as to envisage full integration of TM into conventional medicine.

\section{Discussion}

This study has investigated the public perceptions of the role of TM in the health care delivery system in Sekyere South District, in the Ashanti Region of Ghana.

A study on the Ghana health situation revealed that the primary cause of poor health facilities that affected accessibility is functional to financial constraint (Twumasi, 1988; Buor, 2003). Sowa (2002) has expounded that the declining hospital attendance in 1984 could be traced to the overall economic crises, but continued through 1986 due to the introduction and increase in hospital fees. The study has found that with the current financial and economic strains, most people utilised and patronised the TM because of its relative cheapness. High income earners attend hospital more often than low income earners which is consistent with previous studies (Buor, 2003; Delanyo, 1992; Ensor and Pham-Bich-San, 1996; Pickett and Hanlon, 1990; Habib et al, 1986). TM is generally affordable and therefore utilised mostly by the rural poor who cannot, perhaps afford the orthodox medical care. In this regard, the necessary attention that TM practice deserves should be given. A directorate at the MOH has been created for TM though, this is not enough. Sub-national structures should be provided at both the regional and the district levels to oversee to the dispensation of traditional medical services (Buor, 1993). The government, Non-Governmental Organizations (NGOs) and other stakeholders must therefore see the need to invest in research, education, equipment and other infrastructure which will help make people accrue maximum benefit from TM.

The access to primary health care partly rests on physical distance and possible intervening obstacles (Buor, 2003a; Mensah, 2003: unpublished doctoral thesis). Longer distances and travel times result in lower utilization of health care (Buor, 2003). This study has shown that the TMPs both males and females were present in the district. Each community surveyed had at least three (3) TMPs who were distributed evenly across the district to make their services easily accessible to people. With TM, clients do not have to walk and cover long distances for their health care needs as has been observed in other studies in Ghana and elsewhere (Buor, 1993; Okafor, 1990; 1984; Muller et al, 1998). TMPs live and work among the people in the community. They therefore reserve a great deal of confidence in the TMPs and their services. Most of the clients therefore do not take into account the safety, quality and the standard of service of TM.

The study found that most of the TM offered to clients was perceived to be effective. This was evident in the treatment of such conditions as boils, piles, broken bones/fractures, impotency, infertility, sexual weakness and malaria, typhoid fever, mental disorder, hypertension, among others. Respondents claimed that as far as these diseases are concerned, the TM is more effective than the $\mathrm{OM}$ as they responded favourably to the various medicines used. Most respondents are psychologically comfortable with the use of the TM because they perceived the system to be embedded in their own socio-cultural roots. This is in consonance with other studies (Peltzer et al, 2008; Buor, 1993; Twumasi, 1988). Necessary recognition must be given to the TMPs and their practices so as to encourage them to put in much effort in the primary health care. However, the safety of use of TM is questionable. Quite a number of TMPs practised under unhygienic conditions and environs which could develop further infections to their clients and complicate their health problems. It is evident that the TMPs did not have a standard and accurate dosage for medicines prescribed and described for clients, rather they resort to "trial and error" method for medicine administration (WHO, 2002). This pose serious challenge to acceptable and sound medical practices envisage by the $\mathrm{MOH}$ for the citizenry. Stakeholders and the Ghana Health Service are to organize regular training and education programmes for TMPs on the need to practise in uncontaminated environment. Also, medical administration based on "trial and error" should be avoided to avert the consequence of over dosages and under dosages of medications. 
The TMPs were managing almost every condition presented to them. They effectively treated such conditions as arthritis/rheumatism, piles, infertility, malaria, typhoid fever, broken bone, boil and diseases of psychic nature (Buor, 1993). It was envisaged that TM will never entirely disappear from the traditional society of the Sekyere South District because it is potent and viable in treating most medical conditions presented by the patients. Much effort should be offered by the government and the health sector to ensure total modernisation, standardisation and improvement of TM so that better services could be rendered by the TMPs in the health care delivery as observed by other studies (Yuri et al, 2007).

One of the most important mechanisms in any medical system which guarantees the safety of patients and assures effective treatment of diseases is the ability of the system to ensure prompt referral of patients from one system to another. No wonder, the Acting Director of TAMP, MOH stated that cross-referral of cases between the TMPs and OMPs would improve health care delivery for people when he addressed the Fourth TM Week held at Koforidua on September 6, 2003 (The Ghanaian Times, 2003). Any attempt to integrate traditional and orthodox medical systems will see much difficulty, although over $96 \%$ of all TMPs surveyed shown interest. The rife of rivalry between the two medical systems is a great bottleneck to undermine the process, as the collaboration between OMPs and TMPs remained unofficial and in some instances non-existing. Only 12 (out of 30) TMPs and 3 (out of 20) OMPs had unofficially referred patients between themselves. Medical pluralism was practised among the majority of health care users which vindicated other studies (Twumasi, 1988). There is therefore the need to have a mechanism in place to properly coordinate the system. There should be a smooth and official referral mechanism between the health care providers. Ghana Health Service Division (GHSD) must, as a matter of urgency, establish a patient referral system between the OMPs and TMPs to protect, promote and enhance the health of clients. Full integration of TM into the OM is needed. This will serve as a catalyst to achieving the long awaited goals of health service delivery and the health for all policy as explicated in the Alma Ata Declaration and as well accelerate efforts towards achieving the health related MDGs.

\section{Limitations of the study}

The research design adopted in this survey had some limitations that one way or the other influenced the findings. The study used interviews and key informants as the main source of primary data and relied on participants' self-report of historical events and perceptions to assess the role of TM. The issues with efficacy and safety of TM use were measured with the respondents' responses. No chemical or scientific tests were conducted due to lack of logistics. This inevitably gave rise to the question of interviewer bias and social desirability bias being presented. No statistical comparisons could be made because the study methodology was set as qualitative, and the results are less accurate than they would have been, using quantitative data.

\section{Conclusion}

The role of TM is significant particularly in rural Ghana in the treatment of life-threatening and dreadful ailments. TM is affordable, readily available, hence, easily accessible and therefore utilized as such. There are other complex psycho-social and cultural factors associated with TM use. It is seen to be embedded in the personal values, religious and health philosophies of people. The development of the system should not end up in political polemics. Real, concrete and iterative action should follow the recognition of the contribution of TM to the health care of the people.

\section{References}

Addae-Mensah, I. (1992). Towards a national scientific basis for herbal medicine-a phytochemists two decade contribution. Accra Ghana, University Press.

Agyare, C., Mensah, A. Y., \& Osei-Asante, S. (2006). Antimicrobial activity and phytochemical studies of some medicinal plants from Ghana. Boletin Latinoamericano y del Caribe de Plantas Medicinales y aromaticas, Chile.

Akerele, O. (1984). World Health Organisation's (WHO) Traditional Medicine Programme: Progress and Perspective. WHO Chronicle, 38 (2), 76-81.

Akerele, O. (1987). The Best of Both Worlds: Bringing Traditional Medicine Up to Data. Social Science and Medicine, 24 (2), 177-181. http://dx.doi.org/10.1016/0277-9536(87)90250-4

Aluwihare, A. P. R. (1982). Traditional and Western medicine working in tandem. World Health Forum, 3 (4), 395-397, 450.

Awadh, A. N. A., Al-rahwi, K., \& Lindequist, U. (2004). Some Medicinal Plants Used in Yemeni Herbal Medicine to Treat Malaria. Afr. J. CAM., 1, 72-76. 
Buor, D. (2008). Analysing the socio-spatial inequities in the access of health services in sub-Saharan Africa: Interrogating geographical imbalances in the uptake of health care. Professorial Inaugural Lecture. Great Hall, KNUST, Kwame Nkrumah University of Science and Technology, Kumasi, Ghana. October 9, 2008.

Buor, D. (2004). Accessibility and utilisation of health services in Ghana. (PhD Thesis presented at Maastricht University. Defended in June 2004). Netherlands Foundation for Advancement of Tropical Research (WOTRO), Netherlands and Netherlands Institute for Health Services Research (NIVEL), Twin Design (Printers), Netherlands, 272pp.

Buor, D. (2003). Analysing the primacy of distance in the utilization of health services in the Ahafo-Ano South district, Ghana. Int J Health Plann Mgmt, 18, 293-311.

Buor, D. (2002). The predominance of distance in the utilisation of health services in the Kumasi Metropolis, Ghana. An international journal on human geography and environmental sciences. Geo Journal, 56 (2), 145-157. http://dx.doi.org/10.1023/A:1022452311911

Buor, D. (1993). The Impact of Traditional Medicine on Health Delivery Services in Ghana: The Ashanti Situation. Journal of the University of Science and Technology, 13 (3), October, 1993.

Curtis, S. \& Taket, A. (1995). Health and Societies: Changing Perspective. London, New York, Edward Arnold.

Delanyo, D., Boohene, A., Ntow, S., Matemara, B., Attipoe, D., \& Ankra, A. V. (1992). What does the public wants from us? Research report on a study of user satisfaction with services in government health facilities in the Eastern Region of Ghana. Koforidua MOH, Eastern Region of Ghana, 1992.

Ensor, T. \& San R. B. (1996). Access and Payment for Health Care: the poor of Northern Vietnam. International Journal of Health Planning and Management, 11 (1), 69-83. http://dx.doi.org/10.1002/(SICI)1099-1751(199601)11:1<69::AID-HPM414>3.0.CO;2-P

Habib, O. S. \& Vaughan, J. P. (1986). The Determinants of Health Service Utilisation in South Iraq: A Household Survey. International Journal of Epidemiology, 15 (3), 395-403. http://dx.doi.org/10.1093/ije/15.3.395

Hougen, H. K. \& Sesiah-Lewis, P. (1998). Traditional Medicine and primary health care. An Introduction and Selected Annotated Bibliography. EPC Publications, 18, 21. LSHTA.

Kaboru, B. B., Falkenberg, T., Ndulo, J., Muchimba, M., Solo, K., \& Faxelid, E. (2006). Communities’ views on prerequisites for collaboration between modern and traditional health sectors in relation to STI/HIV/AIDS care in Zambia. Health Policy, 78 (2-3), 330-339. http://dx.doi.org/10.1016/j.healthpol.2005.10.001

Kofi-Tsekpo, M. W. (2006). Research on Traditional Medicines used for the Treatment of Malaria in WHO Africa Region. Africa Herbal Antimalaria Conference/Meeting, Nairobi, Kenya, $20^{\text {th }}-22^{\text {nd }}$ March 2006.

Leighton, C. \& Foster, R. (1993). Economic impact of malaria in Kenya and Nigeria Abt Associates. Health Financing and Sustainability Project. Bethesda, Maryland.

Ministry of Health. (MOH) (2006). Health Sector 5-Year Programme of Work 2002-2006.

MOH. (2008). Health Sector Programme of Work 2007: Independent Review (Draft Report 2008). Ministry of Health, Accra-Ghana

Mwangi, J. W. (2004). Integration of Herbal Medicine in National Health Care of Developing Countries. Editorial East Africa Medical Journal, October, 2004.

Ndulo, J. (2001). Traditional Healers in Zambia and their care for patients with Urethral/vaginal discharge. Journal of Alternative and Contemporary Medicine, 7, 529-36. http://dx.doi.org/10.1089/10755530152639756

Osei-Edwards Rebecca. (2003). Mampong Makes Headway-Daily Graphic. Monday, October, 27, No. 148961.

Peltzer, K. \& Mngqundaniso, N. (2008). Traditional Healers and Nurses: A Qualitative Study on Their Role on STIs including HIV and AIDS in KwaZulu-Natal, South Africa. Afr. J. Trad. CAM, 5 (4), 380-386. http://dx.doi.org/10.1186/1471-2458-8-255

Peltzer, K., Preez, N. F., Ramlagan, S., \& Fomundam, H. (2008). Use of traditional complementary and alternative medicine for HIV patients in KwaZulu-Natal, South Africa. BMC Public Health, 8, 255.

Peltzer, K. (2000a). Perceived treatment efficacy of the last experienced illness episode in a community sample in the Northern Province, South Africa. Curationis, 23, 57-60.

Peltzer, K. (2003). HIV/AIDS/STD knowledge, attitudes, beliefs and behaviours in a rural South African adult population. South African Journal of Psychology, 33, 250-60. 
Pickett, G. \& Hanlon, J. J. (1990). Public Health Administration and Practice. St. Louis Times Mirror/Mosby College Publishing.

The Ghanaian Times. (2003). National Health Insurance Scheme (NHIS). Widens herbalist others to be licensed for programme. The Front page, Tuesday, September 9, 2003. Issue of the Ghanaian Times (No. 14163 ISSN 0855-1503).

Twumasi, P. A. (1975). Medical Systems in Ghana: A Study in Medical Sociology. Accra-Tema, Ghana Publisher Corporation.

Twumasi, P. A. (1988). Social foundation of the interplay between traditional and modern systems. Accra: Ghana Universities Press (Inaugural Lecture).

UNAIDS/WHO. (2008). AIDS Epidemic Update, December 2008.

UNAIDS/WHO. (2008). Epidemiological fact sheet on HIV and AIDS: Core data on epidemiology and response, Nepal. World Health Organization, Geneva, pp. 4-20.

UNAIDS. (2003). AIDS Epidemic Updates, 2003 Geneva.

Wasti, S. P., Simkhada, P., Randall, J., \& van Teijlingen, E. (2009). Issues and Challenges of HIV/AIDS Prevention and Treatment Programme in Nepal. Global Journal of Health Science, 2009.

WHO. (2008). HIV/AIDS Strategy in the African Region: A Frame Work for Implementation. Fiftieth Session, Ouagadougou, Burkina Faso, $28^{\text {th }}$ August- $2^{\text {nd }}$ September, 2008.

WHO. (2006). HIV/AIDS in Europe: moving from death sentence to chronic disease management. In: Matic, S., Lazaarus, J. F., \& Donoghoe, M. C. (Eds.), pp. XII.

WHO. (2005). National policy on Traditional Medicine and regulation of Herbal Medicines. Report of the WHO global survey. World Health Organization, Geneva. May, 2005.

WHO. (2004). Guidelines on Registration of Traditional Medicines in the WHO African Region. Traditional Medicine Programme Department of Essential Drug and Medicines Policy Geneva. WHO Regional Office for Africa, 2004 AFR/TRM/04.1

WHO. (2002). World Health Organisation Traditional Medicine Strategy 2002-2005. WHO/EDM/TRM/2002.1Original: English Distribution: General. WHO, Geneva.

WHO. (2002). Health for all Policy For the $21^{\text {st }}$ Century in the Africa Region-Agenda 2000-WHO Regional Office for Africa.

WHO. (2001). Promoting the Role of Traditional Medicine in Health System: A Strategy for the African Region. WHO Regional Office for Africa.

WHO. (2000). General Guidelines for Methodologies on Research and Evaluation of Traditional Medicine WHO/EDM/TRM/2000.1. World Health Organization, Geneva

World Health Organization. (2000). African Summit on Roll back malaria. WHO press release. [Online] Available: http://www.who.int

WHO. (1998). Background Information for Reviewing the Traditional Medicine Cabinet Paper. WEHO/EDM/HQ WHO. (1996). Traditional Medicine-WHO Information fact sheets. Fact sheet N134, September 1996.

WHO. (1978). The Promotion and Development of Traditional Medicine. World Health Organization Technical Report Series 622 Geneva.

WHO. (1976). Expects Report Committee on Traditional Medicine. WHO, Geneva.

Wilkinson, D. \& Wilkinson, N. (1998). HIV infection among patients with sexually transmitted diseases in rural South Africa. International Journal of STD AIDS, 9, 736-39. http://dx.doi.org/10.1258/0956462981921486

Xue, C. C., Zhang, A. L., Lin, V., \& Da Costa, C. (2010). Contemporary and Alternative Medicine Use in Australia: A National Population-Based Survey. World Health Organisation Collaborating Centre for Traditional Medicine, School of Health Sciences. Melbourne, Melbourne, Australia.

Yuri, N. C., Jamie, M. G., Basdeo, L., Blades, A., Marie-Joanna, F., Gomes, N., Janjua, M., \& Adelle, S. (2007). Perceived efficacy of herbal remedies by users accessing primary healthcare in Trinidad. BMC Complementary and Alternative Medicine, 7, 4. http://dx.doi.org/10.1186/1472-6882-7-4 
Table 1. Accessibility and Usage of Traditional Medicine

\begin{tabular}{|l|c|c|}
\hline Economic Parameter & $\mathrm{n}=70$ & $\%$ \\
\hline Cheap & 41 & 58.6 \\
\hline Moderate & 24 & 34.3 \\
\hline Expensive & 5 & 7.1 \\
\hline
\end{tabular}

Table 2. Medical Conditions/Diseases treated by the TMPs

\begin{tabular}{|l|c|c|}
\hline Medical Conditions/Diseases & TMPs (N=30) & 13.3 \\
\hline Impotency/Infertility/Sexual Weakness & 4 & 16.7 \\
\hline Malaria/Typhoid/Jaundice & 5 & 16.7 \\
\hline $\begin{array}{l}\text { Rheumatism/ Arthritis/Broken } \\
\text { bones/Fracture }\end{array}$ & 4 & 13.3 \\
\hline Boil/ Pile & 1 & 3.3 \\
\hline Menstrual Pains/STIs/HIV/AIDS & 2 & 6.7 \\
\hline Convulsion/hypertension/ & 4 & 13.3 \\
\hline Snake/Dog Bite/Cutlass Wound & 1 & 3.3 \\
\hline Mental illness & 4 & 13.3 \\
\hline Others & 5 & \\
\hline
\end{tabular}

Table 3. Efficacy of Traditional Medicine

\begin{tabular}{|l|c|c|c|c|}
\hline \multirow{2}{*}{ Category } & \multicolumn{2}{|c|}{$\mathrm{n}$} & \multicolumn{2}{c|}{ \% } \\
\cline { 2 - 5 } & User & OMP & User \\
\hline Bad & 5 & 3 & 7.1 & 15.0 \\
\hline Good & 23 & 6 & 32.9 & 30.0 \\
\hline Very Good & 42 & 11 & 60.0 & 55.0 \\
\hline
\end{tabular}

Table 4. Integrating Traditional Medicine into Biomedical System

\begin{tabular}{|l|c|c|}
\hline Category & $\mathrm{n}=30$ & $\%$ \\
\hline Yes & 29 & 96.7 \\
\hline No & 1 & 3.3 \\
\hline
\end{tabular}

